\title{
The Role of 3D \& 4D Ultrasonography in Diagnosis of Fetal Head and Neck Congenital Anomalies
}

\author{
Mohamed Salah Elfeshawy ${ }^{1}$, , Wafik Ebrahim Aly ${ }^{2}$, Mahmoud Abouzeid Abouzeid ${ }^{3}$ \\ Radiodiagnosis Department, Faculty of Medicine (For Boys), Al-Azhar University, Cairo, Egypt \\ Email address: \\ mohamedelfeshawy@azhar.edu.eg (M. S. Elfeshawy), Drwafikebrahim@gmail.com (W. E. Aly), \\ mahmoudabouzed@gmail.com (M. A. Abouzeid) \\ *Corresponding author
}

To cite this article:

Mohamed Salah Elfeshawy, Wafik Ebrahim Aly, Mahmoud Abouzeid Abouzeid. The Role of 3D \& 4D Ultrasonography in Diagnosis of Fetal Head and Neck Congenital Anomalies. International Journal of Medical Imaging. Vol. 7, No. 4, 2019, pp. 81-90.

doi: 10.11648/j.ijmi.20190704.11

Received: October 25, 2019; Accepted: November 20, 2019; Published: November 26, 2019

\begin{abstract}
The amazing tecnology of 3D imaging enables the examination of the fetal central nervous system simultaneously in the three orthogonal planes, better defining the spatial relationship of CNS structures and malformations. The multiplanar mode is utilized to navigate through the volume, observing information on a particular structure in each of the three symmetrical planes. The aim of this stuyd is to evaluate the role of $3 \mathrm{D} / 4 \mathrm{D}$ ultrasound in assessment of fetal head and neck congenital anomalies. This is prospective study including thirty pregnant females during the second trimester of pregnancy with 2D suggestion of fetal head and neck congenital anomalies. 42 anomalies were detected from examination of thirty pregnant females. In addition, a higher incidence of face and neck anomalies over CNS anomalies was noted. (57.2\% versus $42.8 \%$ ). We concluded that 2D US remains the gold standard in assessment of fetal anomalies and 3D/4D US, along these lines, isn't a screening system however an aide to 2D US for those embryos in whom anomalies are as of now decided or associated on the premise with standard sonography.
\end{abstract}

Keywords: 3D and 4D Ultrasound, Congenital Anomalies, Head and Neck

\section{Introduction}

Congenital deformities represent $20-25 \%$ of perinatal demises. Presently, numerous hereditary and different issue can be diagnosed early in pregnancy. Prenatal diagnosis utilizes different noninvasive and invasive procedures to decide the wellbeing of the condition or any abnormality in an unborn fetus [1].

Techniques of fetal visualization:

Noninvasive techniques; Ultrasound, Fetal echocardiography, Magnetic resonance imaging (MRI).

Invasive techniques; Embryoscopy, Fetoscopy [1].

In Egypt, infant mortality rate due to congenital anomalies is about $15 \%$ of all infant death and also leading to elevated morbidity in the neonatal period.

CNS deformities are the second most common category of congenital anomaly, after congenital heart disease. The fetal face is a critical piece of the structural survey, since facial anomalies can give much data cautioning us to the likelihood of related anomalies at different levels of the fetal anatomy. It is well known that some facial and encephalic structures share the same embryologic origin [2].

Ultrasound screening of structural fetal malformations is mainly based on the utilization of ultrasound during the second trimester of pregnancy. The Royal College of Obstetricians and Gynecologists recommends that the second trimester fetal anatomical exam be performed somewhere in the range of 20 and 23 weeks, others suggest that the second trimester ultrasound ought to be performed following 18 weeks and before 22 weeks gestation [3].

The utilization of two-dimensional ultrasound in obstetrics has been well settled. However, there are numerous downsides of 2D US imaging. To start with, the administrator needs to reconstruct the three-dimensional structure mentally by joining $2 \mathrm{D}$ US pictures and the assessed position of the ultrasound probe, this recreation procedure is administrator dependent. Second, it might be hard to find or achieve a portion of the attempted scan planes if the embryo is in an 
uncomplimentary position [4].

Standard 2D image is comprised of a progression of thin cuts and just one cut can be seen. In 3D US a volume of echoes is made, which can be processed digitally and concealed to deliver life-like images of the fetus. It is conceivable to quantify distance, area and volume from volume information with 3D ultrasound. Three-dimensional ultrasound information can be cut in any direction, taking into consideration any distance across or cross-sectional area of the organ to be estimated. 4D US adds movement to the 3D imaging presentation. With 4D ultrasound, the life-like fetal images can be delivered to move in real time. 3D/4D US enables sonographers to move from a $3 \mathrm{D}$ mental recreation of $2 \mathrm{D}$ pictures to real $3 \mathrm{D}$ representation of anatomical structures [5].

Defenders of 3D US examination have contended that volumetric estimations from 3D ultrasound scan are increasingly precise and that the two clinicians and parents can all the more likely value a specific deformity with a $3 \mathrm{D}$ scan than a standard 2D scan. Also, there is the likelihood of expanding mental holding between the parents and the baby [6].

3D/4D US applications are numerous and mixed Their utilization in fetal medicine differs with the nature of the tissue to be scanned and the type of every organ system presents, versus the benefits of every ultrasound application. The investigators expressed that 3D/4D US has been broadly connected to the investigation of the fetus. Fetal applications incorporate a wide range of anatomical evaluation, morphometric and volumetric, along with functional evaluation. 3D/4D US gives numerous points of interest in fetal imaging; nevertheless, its involvement to improve the precision of fetal scanning over rates accomplished with $2 \mathrm{D}$ US, stays to be established [7].

The central nervous system is a frequent site for inborn defromities. Neural tube defects (NTDs), for example, anencephaly and spina bifida, which due to failure of fusion of the neural tube during embryonic development. Central nervous system (CNS) anomalies are the second most common class of congenital anomaly, after congenital heart disease [8].

Ultrasound (US) discovery of pre-birth central nervous system (CNS) anatomic deformities is significant in settling on choice about therapeutic termination. It is a non-invasive method, which is progressively satisfactory by patients. Many examinations have demonstrated an accuracy of $92 \%$ to $99.7 \%$ for US recognition of CNS anatomic deformities [9].

\section{Methods}

The study was done at Al Hussein University Hospital, and the cases were collected during a period starting from 1st of October 2017 to the 1 st of June 2018.

It was conducted on thirty pregnant females during the second trimester of pregnancy with 2D suggestion of fetal head and neck congenital anomalies

Over the study period 30 pregnant females with head and neck anomalies were examined and evaluated sonographically. They came for routine antenatal screening or for confirmatory advice from another place.

\subsection{Inclusion Criteria}

1. The maternal age ranged from 19 to 39 years.

2. Gestational age: second trimester.

3. Maternal risk factors (family history - positive consanguinity - previous anomalous delivery exposure to infection - DM).

4. US findings suggestive of fetal anomalies.

\subsection{The Study Subjects Were Classified into: CNS Anomalies and Face \& Neck Anomalies}

Informed consent was taken from all examined pregnant females.

\subsection{Each Patient Included in the Study Was Subjected to}

Full history taking (maternal age, gestational age, history of consanguinity positive family history of fetal anomalies, history of DM or other risk factors)

\subsection{Ultrasound Examination Including}

A Traditional 2D ultrasound scans to evaluate:

1. Fetal brain: in axial plane through transthalamic, transventricular, and transcerebellar views and measures BPD, HC, width of lateral ventricle width of third ventricle, cerebellar diameter, cistern magna diameter, and examine skull shape and presence of cavum septum and corpus callosum in sagittal or coronal planes.

2. Fetal face: In axial views through orbits, maxilla and alveolar ridge. In sagittal views through facial profile (true mid-sagittal) and ear (Para-sagittal). In oblique views through lips and palates.

3. Fetal neck: is obtained in sagittal, axial, and coronal planes to assess the cervical spine, and to assess for masses.

\subsection{Preliminary Diagnoses Were Made Based on the Findings Detected After Completion of the 2D Scan}

The cases that needed more evaluation by $3 \mathrm{D} / 4 \mathrm{D}$ US it's done by using volume convex probe

A 3D US volume was taken to scan the head and neck regions as well as the area of interest when $2 \mathrm{D}$ US detected or suggested an abnormality.

Three dimensional and four-dimensional ultrasound scans evaluated by:

1. Multiplanar view: it examines the brain and face in three spatial planes (axial, sagittal and coronal) thus obtaining an infinite series of images useful to complete evaluation of the complex structure of brain and face

2. Surface rendering: to visualize facial surface (lips and ear).

3. The $3 \mathrm{D} / 4 \mathrm{D}$ images were compared with the $2 \mathrm{D}$ images and the results were analyzed to determine if the equal, extra or conflicting data were attained 


\section{Results}

This study was conducted on thirty pregnant females during the second trimester of pregnancy with 2D suggestion of fetal head and neck congenital anomalies or with risk factors association. From the thirty pregnant females we detected 42 anomalies.

We noticed higher incidence of face and neck anomalies over CNS anomalies (57.2\% versus $42.8 \%$ ).

Table 1. Distribution of CNS anomalies according to its number and percent.

\begin{tabular}{llll}
\hline Type of anomaly & No. & $\begin{array}{c}\text { \% in CNS } \\
\text { anomalies }\end{array}$ & $\begin{array}{l}\text { \% in total } \\
\text { anomalies }\end{array}$ \\
\hline Anencephaly & 3 & 16.7 & 7.14 \\
Holoprosencephaly & 6 & 33.3 & 14.28 \\
Ventriculomegaly & 4 & 22.2 & 9.52 \\
Choroid plexus cyst & 2 & 11.1 & 4.76 \\
Occipitomeningeoencephalocele & 3 & 16.7 & 7.14 \\
\hline
\end{tabular}

Table 2. Distribution of face and neck anomalies according to its number and percent.

\begin{tabular}{llll}
\hline Type of anomaly & No. & $\begin{array}{l}\text { \%in face and } \\
\text { neck anomalies }\end{array}$ & $\begin{array}{l}\text { \% in total } \\
\text { anomalies }\end{array}$ \\
\hline Thyroid goiter & 1 & 4.2 & 2.38 \\
Cystic hygroma & 3 & 12.5 & 7.14 \\
Cleft lip & 10 & 41.67 & 23.8 \\
Arrhinia & 2 & 8.33 & 4.76 \\
Single eye/ cyclopia & 2 & 8.33 & 4.76 \\
Proboscis & 4 & 16.67 & 9.52 \\
Macroglossia & 2 & 8.33 & 4.76 \\
\hline
\end{tabular}

Table 3. Number and percentage of cases according to the maternal age.

\begin{tabular}{lll}
\hline Maternal age & No & \% \\
\hline Below the age of 30 years & 12 & 40 \\
Above the age of 30 years & 18 & 60 \\
Total & 30 & 100 \\
\hline
\end{tabular}

Table 4. Type, number and percent of anomalies according to maternal age.

\begin{tabular}{|c|c|c|c|c|c|}
\hline \multirow{2}{*}{ Type of anomaly } & \multicolumn{2}{|c|}{ Below 30 years (16 anomalies) } & \multicolumn{2}{|c|}{ Above 30 years (26 anomalies) } & \multirow{2}{*}{ Total \% (42) } \\
\hline & No. & $\%$ & No. & $\%$ & \\
\hline Anencephaly & 0 & 0 & 3 & 11.53 & 7.14 \\
\hline Holoprosencephaly & 1 & 6.25 & 5 & 19.23 & 14.28 \\
\hline Ventriculomegaly & 4 & 25 & 0 & 0 & 9.52 \\
\hline Occipitomeningeo encephalocele & 0 & 0 & 3 & 11.53 & 7.14 \\
\hline Cleft lip & 2 & 12.5 & 8 & 30.78 & 23.8 \\
\hline Single eye/ cyclopia & 1 & 6.25 & 1 & 3.85 & 4.76 \\
\hline proboscis & 0 & 0 & 4 & 15.38 & 9.52 \\
\hline Choroid plexus cyst & 1 & 6.25 & 1 & 3.85 & 4.76 \\
\hline Cystic hygroma & 3 & 18.75 & 0 & 0 & 7.14 \\
\hline Thyroid goiter & 1 & 6.25 & 0 & 0 & 2.38 \\
\hline Macroglossia & 2 & 12.5 & 0 & 0 & 4.76 \\
\hline
\end{tabular}

Table 5. Distribution of cases according to multiplicity of anomalies considering the maternal age.

\begin{tabular}{lll}
\hline Maternal age & No. & $\%$ \\
\hline Below the age of 30years & 1 & 16.67 \\
Above the age of 30years & 5 & 83.33 \\
Total & 6 & 100 \\
\hline
\end{tabular}

Table 6. Degree of clarity in $2 D$ US.

\begin{tabular}{lll}
\hline Evaluation & No. of anomalies & Anomaly \\
\hline Not seen & 2 & Single eye \\
Faintly seen & 8 & Cleft lip \\
Well seen & 32 & Rest of anomalies \\
\hline
\end{tabular}

Table 7. Degree of clarity in 3D/4D US.

\begin{tabular}{lll}
\hline Evaluation & No. of anomalies & Type of anomalies \\
\hline Not seen & 1 & Small sized choroid plexus cyst \\
Faintly seen & 5 & Sizeable choroid plexus cyst, ventriculomegaly and one case of macroglossia \\
Well seen & 36 & Rest of anomalies \\
\hline
\end{tabular}

Table 8. Different percent of clarity by $2 D$ and $3 D / 4 D U S$.

\begin{tabular}{lll}
\hline Evaluation & \% in 2D US & \% in 3D/4D US \\
\hline Not seen & 4.76 & 2.38 \\
Faintly seen & 19 & 11.9 \\
Well seen & 76.2 & 85.71 \\
\hline
\end{tabular}


Table 9. Detection of cleft lip by $2 D$ US and 3D/4D US.

\begin{tabular}{lll}
\hline Evaluation & 2D US & 3D/4D US \\
\hline Faintly seen & 8 cases $(80 \%)$ & 0 \\
Well seen & $2 \operatorname{cases}(20 \%)$ & 10 cases $(100 \%)$ \\
\hline
\end{tabular}

Table 10. Fate of the pregnancies with congenital anomalies.

\begin{tabular}{lll}
\hline Fate of pregnancy & Number & Present \\
\hline Elective abortion & 17 & $56.6 \%$ \\
Delivery & 11 & $36.7 \%$ \\
IUFD & 2 & $6.7 \%$ \\
\hline
\end{tabular}

Table 11. Type of anomalies according to completion of pregnancy.

\begin{tabular}{ll}
\hline Type of anomaly & Number of cases \\
\hline Cleft lip & 4 \\
Choroid plexus cyst & 2 \\
Ventriculomegaly & 2 \\
Cystic hygroma & 3 \\
\hline
\end{tabular}

Table 12. Type of anomalies and number of cases IUFD.

\begin{tabular}{ll}
\hline Type of anomaly & Number of cases \\
\hline Thyroid goiter & 1 \\
Holoprosencephaly & 1 \\
\hline
\end{tabular}


Figure 1. Case No 1.

A 26-year-old, no previous antenatal US, un remarkable both past medical and family histories, with the past youngster being conceived at term with no inherent anomalies.

US findings:

(A, B, C and D): 2D ultrasound images: with different orthogonal planes showing: Mono- ventricle anteriorly, absent cavum septi pellucidi (CSP)

(E and F): 3D surface rendered ultrasound images of the same fetus with facial anomalies as described by arrows

Diagnosis: Alobar Holoprosencephaly with cyclopia and arrhinia 




Figure 2. Case No 2.

A 23-year-old, previous antenatal US, un remarkable both past medical and family histories, with no past conveyance.

US findings: (A and $B)$ :

A: 2D ultrasound axial image: shows bilateral swelling in the neck

B: 3D surface rendered ultrasound images of the same fetus with neck swelling

Diagnosis: Intrauterine thyroid goiter
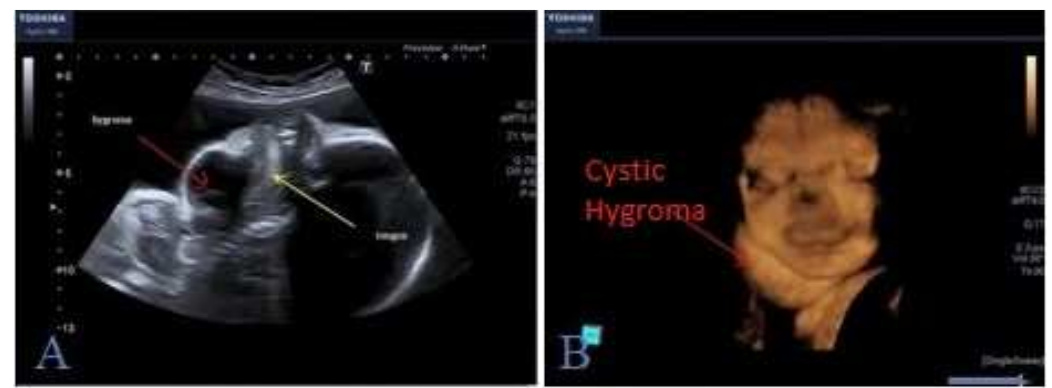

Figure 3. Case No 3.

A 25-year-old, no previous antenatal US, un remarkable both past medical and family histories, with the last caesarian delivery has no associated anomalies US findings: (A and $\mathrm{B})$ :

(A): 2D ultrasound sagittal image: shows anterior diffuse neck swelling

(B): 3D surface rendered ultrasound images of the same fetus with neck swelling

Diagnosis: Cystic hygroma and macroglossia



Figure 4. Case No 4.

A 31-year-old female, no previous antenatal US, un remarkable both past medical and family histories, with no past conveyance.

US findings: $(A, B, C)$ : 2D ultrasound Axial images: shows bilateral cystic lesions are present in the posterior part of lateral ventricles with no associated other anomalies

Diagnosis: Bilateral choroid plexus cysts 

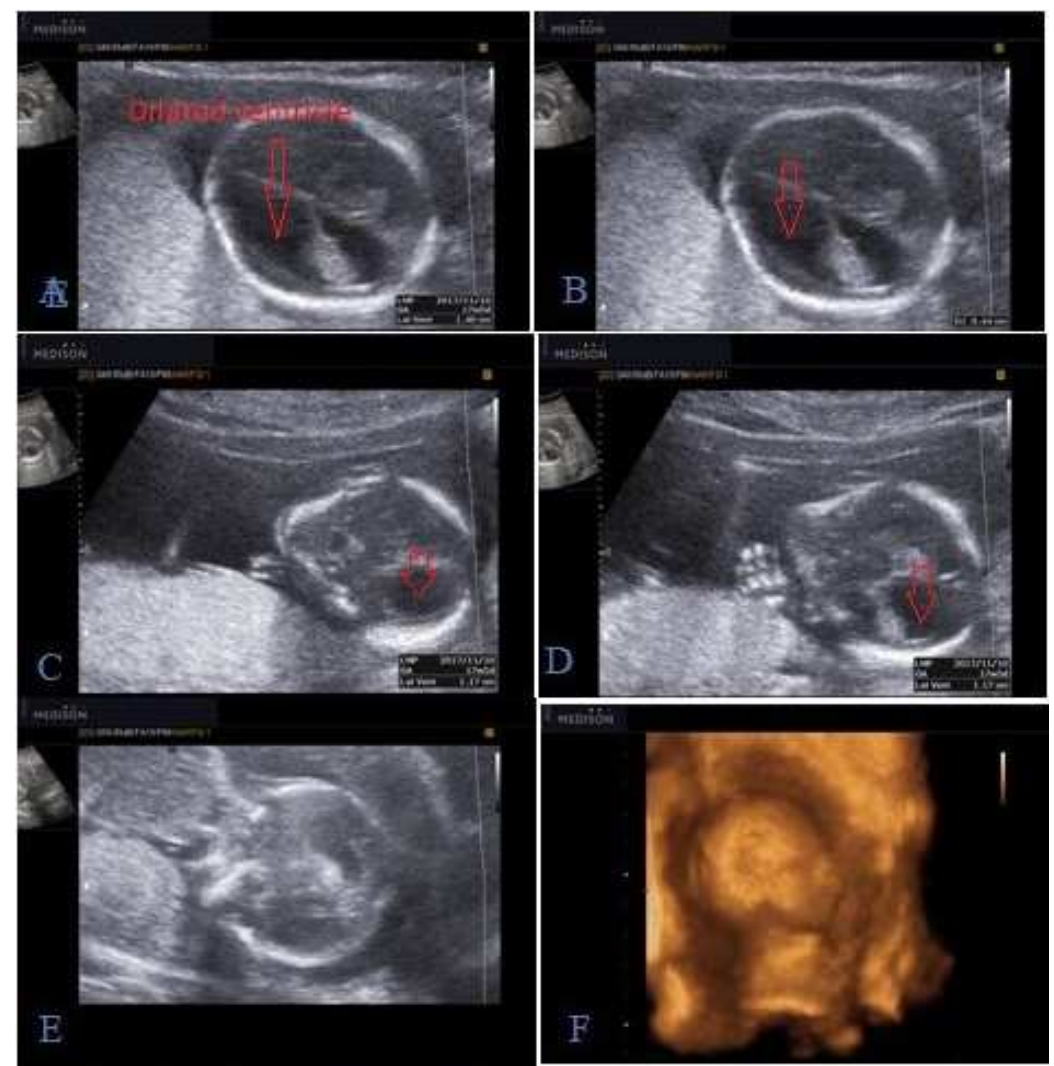

Figure 5. Case No 5.

A 28-year-old female, previous antenatal US done come for follow up, un remarkable both past medical and family histories, with no past conveyance. US findings: (A To F)

(A, B): 2D ultrasound axial images: show dilatation of unilateral side of lateral ventricle

(C, D): 2D ultrasound sagittal images: show dilatation of unilateral side of lateral ventricle

(E): 2D ultrasound coronal image: shows dilatation of unilateral side of lateral ventricle

(F): 3D surface rendered ultrasound images of the same fetus with normal skull view

Diagnosis: Unilateral ventriculomegaly

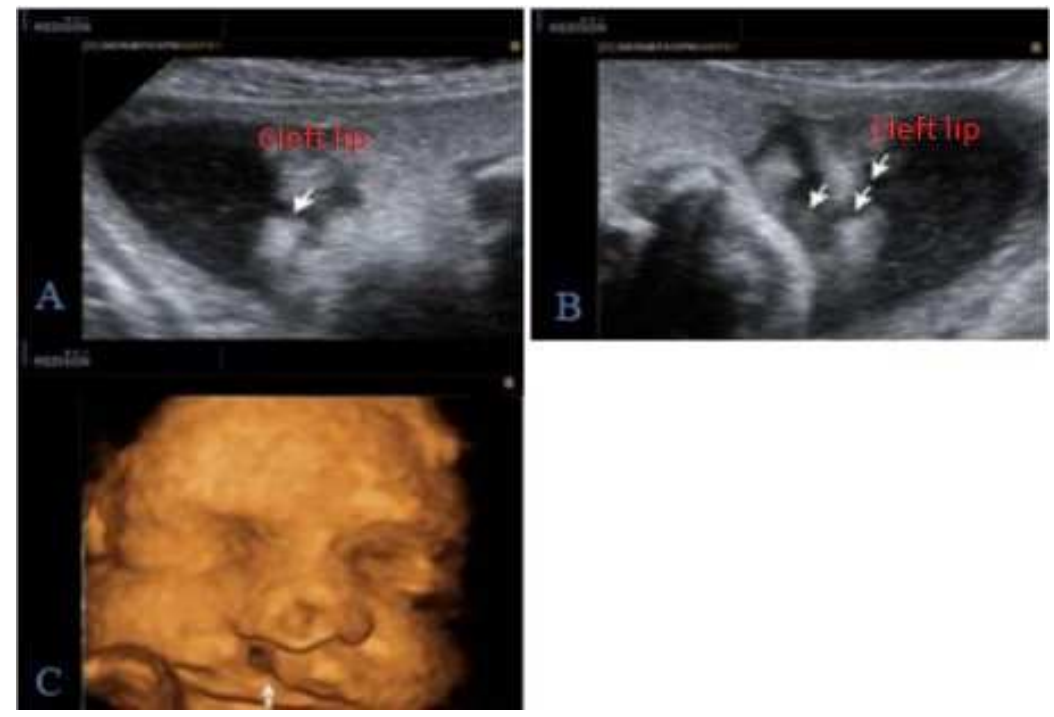

Figure 6. Case No 6.

A 33-years-old woman, with family history of cleft lip and palate, was referred for routine ultrasound examination.

US findings: (A To C)

(A, B): 2D ultrasound images: oblique views of the fetal face with arrows pointing to the unilateral cleft lip.

(C): 3D surface rendered ultrasound image of the same fetus with arrow pointing to unilateral cleft lip.

Diagnosis: Unilateral cleft lip. 


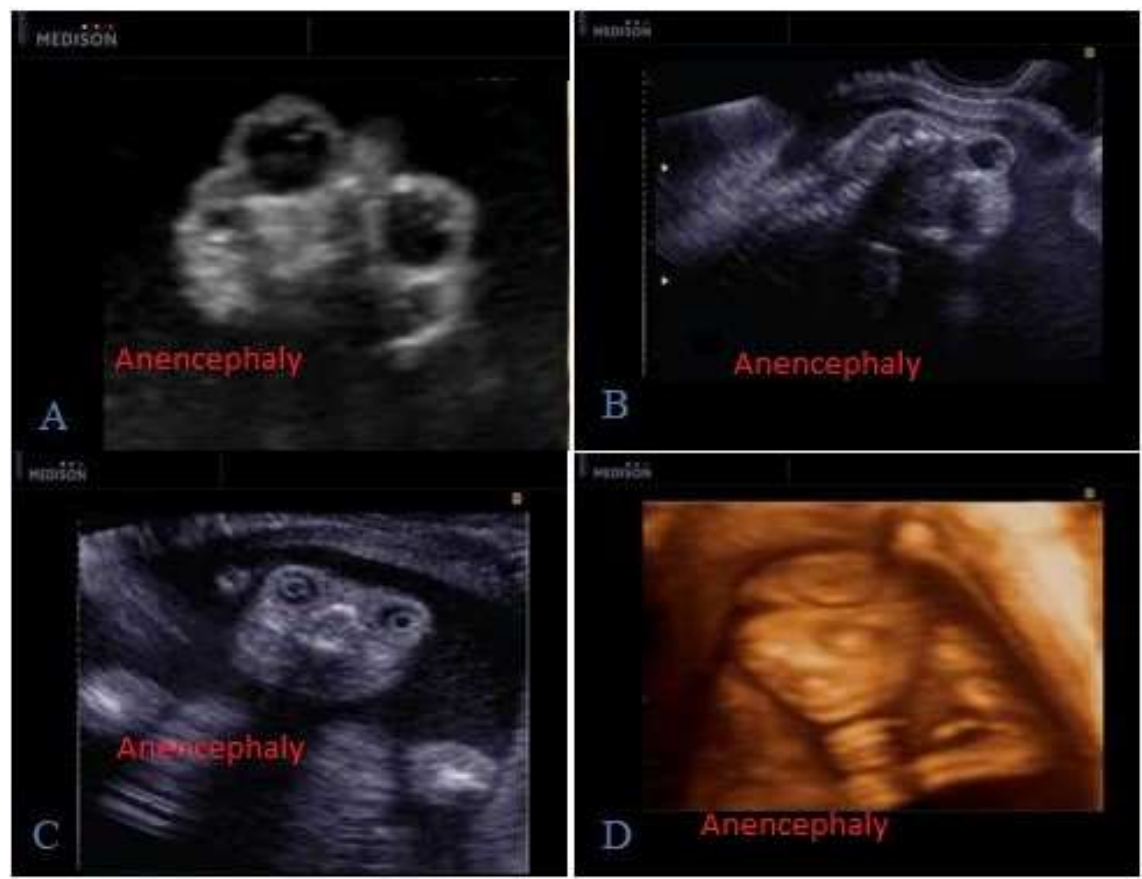

Figure 7. Case No 7.

pregnant woman 35 years presented 20 weeks of gestation without any prior antenatal checkups; previous history shows one vaginal delivery with a normal child.

US findings: 7 (A to D):

(A, B , C): 2D US images show fetal face with prominent eye balls, absent cranium and rudimentary brain.

(D): Surface rendering 3D US image shows the fetal head with prominent eye balls, absent cranium and rudimentary brain giving frog like appearance of the fetal face.

Diagnosis: Anencephaly

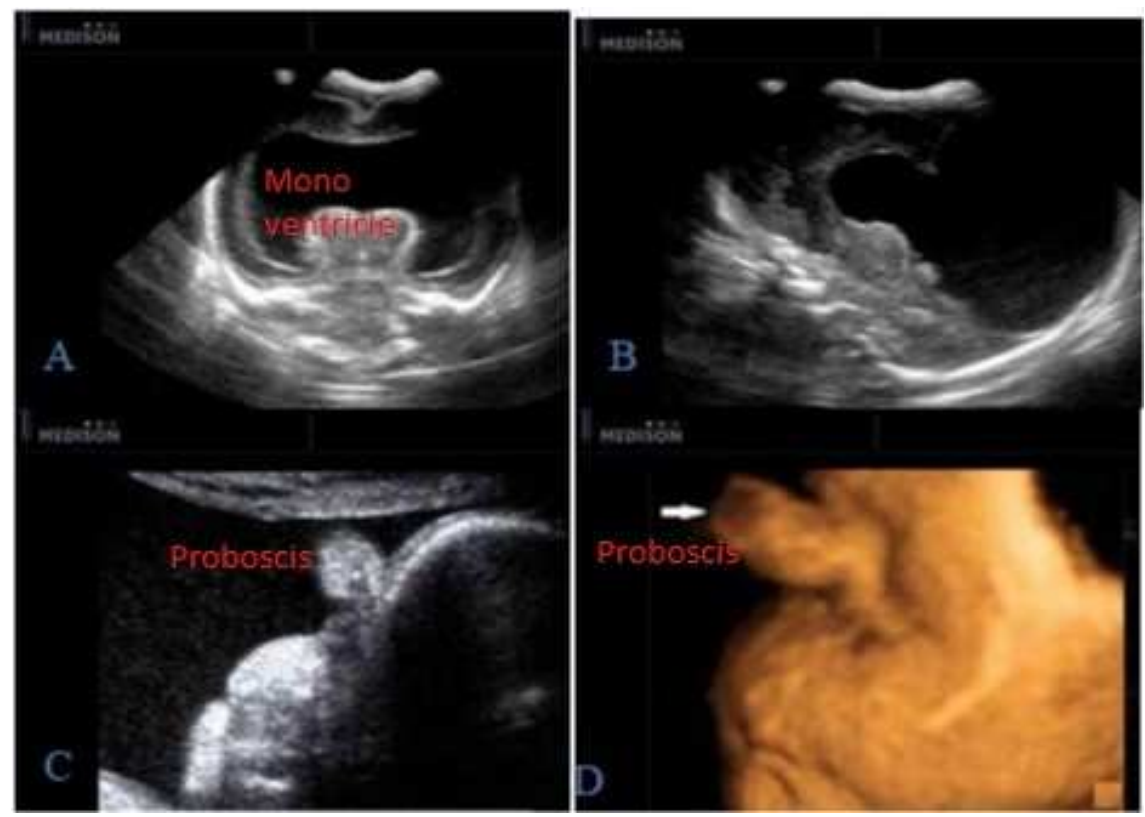

Figure 8. Case No 8.

A 33-year-old, underwent antenatal US. un remarkable both past medical and family histories, with the last baby being born at term with no inherent deformities.

US findings: (A to D)

(A, B): 2D US coronal and sagittal images show: single monoventricle and fused thalami.

(C): 2D image shows flat mid face with absence of normal nose and prominent proboscis

(D): 3D surface rendering sagittal view shows fetal face with proboscis and cyclopia (arrow).

Diagnosis: Semilobar Holoprosencephaly with proboscis. 

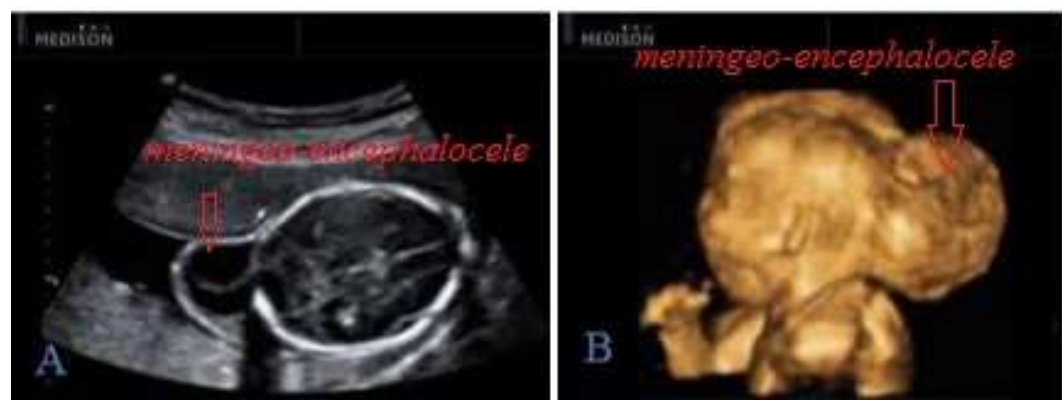

Figure 9. Case No 9.

A 37 year- old woman patient came with five months amenorrhea for a routine antenatal checkup without any previous ultrasonography examinations. US findings: (A and B)

(A): 2D ultrasound image shows posterior skull defect with herniation of meninges and brain tissue outside in the occipital region. (B): 3D image shows sagittal images confirming protrusion of the brain tissue through the skull defect.

Diagnosis: Occipital meningeo-encephalocele.



Figure 10. Case No 10.

A 34-years-old woman, with no positive family history, was referred for routine ultrasound examination, no previous delivery.

US findings: (A to $\mathrm{E})$

(A, B and C): 2D ultrasound image oblique views of the fetal face with arrows pointing to the median cleft lip.

(D and E): 3D surface rendered ultrasound images of the same fetus with median cleft lip.

Diagnosis: Median cleft lip.

\section{Discussion}

We animate a three-dimensional existence where 3D ultrasound turned into a reality connected to the colossal advances of computer size, speed and volume of memory. Inherent deformities are one of the fundamental drivers of physical handicaps, stillbirths and neonatal passing. The careful etiology of most inborn anomalies is unidentified yet hereditary and environmental causes are charged. (10)

In our study we noticed higher incidence of facial and neck anomalies over CNS anomalies (57.2\%versus 42.8\%).

This result agrees with the following studies:

1. Scharf, 2001, in his study of 115 anomalies (in 70 
patients) using both $2 \mathrm{D}$ and 3D/4D US and found that face and neck anomalies were more than CNS anomalies (67\% versus 33\%). (11)

2. Another study done by EL-Mowafi, 2016, performed in King Khaled General Hospital, Saudi Arabia, between January 2002 and June 2003 found that the face and neck anomalies were more and superior to CNS anomalies (72\% versus $28 \%$ ). (12)

We noticed higher incidence of anomalies in ladies above that age 30 compared to those below that age $(60 \%$ of anomalies were detected in cases older than 30 years versus $40 \%$ for those below that age)

3. In agreement with our study Dyson et al., 2000 also found higher incidence of anomalies in cases above 30 years. They studied 63 patients with 103 anomalies and found that the incidence of anomalies is higher above the age of 30 years $(75 \%$ in cases above the age of 30 years $25 \%$ in cases below 30 ). (13)

In our study we compared the efficacy of $2 \mathrm{D}$ US and 3D/4D US in detection of anomalies and we found that:

The anomalies that not seen by 2D US in comparison to $3 \mathrm{D} / 4 \mathrm{D}$ US is $(4.76 \%$ versus $2.38 \%)$

The anomalies that faintly seen by $2 \mathrm{D}$ US in comparison to $3 \mathrm{D} / 4 \mathrm{D}$ US is $(19 \%$ versus $11.9 \%)$

The anomalies that well seen by 2D US in comparison to $3 \mathrm{D} / 4 \mathrm{D}$ US is $(76.2 \%$ versus $85.21 \%)$

The anomaly that not seen by $2 \mathrm{D}$ US is single eye and the anomaly not seen by $3 \mathrm{D} / 4 \mathrm{D}$ US is small choroid plexus cyst

The anomalies that faintly seen by 2D US is cleft lip and anomalies faintly seen by 3D/4D US are sizeable choroid plexus cyst, ventriculomegaly and one case of macroglossia

Regarding cleft lip anomaly, we found that 3D/4D US had superiority in diagnosis in comparison to $2 \mathrm{D}$ US by $(80 \%$ versus $20 \%$ )

All of these results agreed with the following studies:

1. A study conducted by EL-Mowafi, 2016 in King Khaled General Hospital, Saudi Arabia, between January 2002 and June 2003 found that real-time 3D/4D US was helpful for recognizing, affirming, and obviously delineating 34 (47\%) of 72 fetal anomalies, when the method was connected to the fetuses suspected to have anomalies based on 2D US discoveries. The consequences of this examination exhibit that 3D/4D US is helpful for assessing fetal anomalies as an enhancement to 2D US, especially for variations from the norm of the face, ears, fingers and fetal axis. (12)

2. To WW, 2012, who found that presently, standard 2D US is utilized for routine mid-trimester morphology exams. Rendered 3D/4D pictures additionally give more clear tourist spots to the planar perspectives and in the meantime encourage guiding of the family and an interview with a specialist to clarify the variation from the norm. He suggested that, the utilization of rendered pictures alone has been accounted for to acquaint false positives due to the presence of pseudo-clefts that are more often because of rendering artifacts or acoustic shadows, which lead to lost specialty for the ultrasound finding. (14)

3. Chan et al., 2011 had looked at the presentation of $3 \mathrm{D} / 4 \mathrm{D}$ versus 2D Ultrasound in recognizing abnormalities the analytic preferred position of 3D over 2D US extended broadly from 9 to $92.7 \%$ of cases in different studies. (15)

4. In our study we found that $3 \mathrm{D} / 4 \mathrm{D}$ US couldn't provide informative data in one case of choroid plexus cyst, however it's diagnosed by 2D US alone. Also, in 3D/4D US there were cases that faintly seen (Choroid plexus cyst ventriculomegaly and one case of macroglossia).

The previous result agreed with:

1. Lam \& To 2015, they found that there were clearly no false-positives and the explicitness for discovery of cleft lip by 2D US moved toward $100 \%$. The precision of identification of CP within the existence of CL, with a general exactness of around 95\%. Half of the cases of under-analysis or over-conclusion identified with the determination of alveolar ridge clefts. They return this improvement to the enhancements in USG methods and preparing of sonographers. (16)

2. Kim, 2012 who said that 3D US does not seem to add meaningful advantages to 2D US in diagnosis of ventriculomegaly itself. (17)

In our study we found that $3 \mathrm{D} / 4 \mathrm{D}$ US were superior to $2 \mathrm{D}$ US in evaluation of facial anomalies.

In contrast to our result:

1. Abu-Rustum, 2014, found that scanning of the fetal face has been one of the main reasons for the improper utilization of volume sonography for "entertainment ultrasound," and has resulted in abuse by some sonographers and physicians who have capitalized on the emotional component of 3D imaging. (1)

2. Benaceraff, 2006, directed investigation of 26 embryos (20 fetuses with deformities) was accounted for: 57 deformities were analyzed by standard 2D US contrasted with 51 anomalies seen on 3D/4D US. (18)

3. In our study the examination was done firstly with $2 \mathrm{D}$ US then the suspected cases were examined by $3 \mathrm{D} / 4 \mathrm{D}$ US that is agreed with:

4. Baba et al., 2010 that conducting 2D US before 3D US examination is basic to decide the best possible position for $3 \mathrm{D}$ checking thus $3 \mathrm{D}$ US scanning is hard to be performed without the 2D pictures. (4)

5. Lee \& Simpson, 2007 examined two cases (one DandyWalker variation and one cleft lip/palate) recognized by 3D US were false-positives and missed deformities including hypertelorism, small liver cyst, micrognathia, polydactyly and a little omphalocele. In light of these perceptions, detached 3D/4D volume scanning seems lacking to examine fetuses at high hazard for variations from the norm or in whom an anomaly has been found or suspected. As of now, 3D/4D US remains an assistant to standard 2D ultrasound for anomaly screening of the embryo. (19) 


\section{Conclusion}

In Egypt, infant mortality rate due to congenital anomalies is about $15 \%$ of all infant death and also leading to elevated morbidity in the neonatal period.

A standout amongst the most reliably utilized supports for the utilization of obstetric ultrasound is that, precise determination of fetal abnormalities before conveyance can give health care providers and parents various administration alternatives.

In second trimester, an enormous number of fetal head and neck deformities are recognizable by customary 2D US. In any case, this innovation can just give $2 \mathrm{D}$ sectional perspectives of the embryo, while singular sectional planes of the area of interest can't be accomplished within the sight of a negative position of the embryo. Three dimensional US permits the sonographer to assess complex anomalies in different planes, and to store information for post-handling potential outcomes. However, there is no uncertainty that an accomplished sonographer can promptly put together twodimensional planes to make a three-dimensional mental picture of fetal anomalies.

There are still a few issues like surface rendering in oligohydramnios and artifacts of movement during volume rendering that should be settled.

We concluded that 2D US remains the gold standard in assessment of fetal anomalies and 3D/4D US, along these lines, isn't a screening system however an aide to 2D US for those embryos in whom anomalies are as of now decided or associated on the premise with standard sonography.

\section{List of Abbreviations}

$\begin{array}{ll}\text { Abb. } & \text { Full term } \\ \text { 2D US } & \text { Two-dimensional ultrasound } \\ \text { 3D US } & \text { Three-dimensional ultrasound } \\ \text { 4D US } & \text { Four-dimensional ultrasound } \\ \text { BPD } & \text { Biparietal diameter } \\ \text { CNS } & \text { Central nervous system } \\ \text { DM } & \text { Diabetes mellitus } \\ \text { HC } & \text { Head circumference }\end{array}$

\section{Conflict of Interest}

The authors declare that they have no competing interests.

\section{References}

[1] Abu-Rustum RS: A Practical Guide to 3D Ultrasound. Boca Raton, FL. Taylor \& Francis Group; 2014.

[2] Alves C, Júnior E, Nardozza L, et al. Reference ranges for fetal brain fissure development on 3-dimensional sonography in the multiplanar mode. J Ultrasound Med. 2013; 32: 269-77.

[3] Azumendi G, Kurjak A and Gabriel C. 3D sonography in the study of the fetal face. In: Kurjak A, ed. The Fetus in Three
Dimensions Imaging, Embryology and Fetoscopy. United Kingdom: Informa UK Ltd, 2007: 181-214.

[4] Baba K, Okai T, Kozuma S and Taketani Y. Fetal abnormalities: evaluation with real-time-processible threedimensional US-- preliminary report. Radiology 1999; 211: 441-6.

[5] Baba K. Development of 3D ultrasound. In: Kurjek A, ed. Donald School Textbook in Ultrasound of Obstetrics and Gynecology. 3rd ed. New Delhi, India: Jaypee Brothers, 2011: $10-25$.

[6] Chaoui R and Heling KS: Three-dimensional ultrasound in prenatal diagnosis. Curr Opin Obstet Gynecol. 2006; 18 (2) 192-202.

[7] ISUOG Practice Guidelines. performance of first-trimester fetal ultrasound scan. Ultrasound Obstet Gynecol 2013; 41: $102-13$.

[8] Ji EK, Pretorius DH, Newton R, et al.: Effects of ultrasound on maternal-fetal bonding: comparison of two- and threedimensional imaging of obstetric-gynecol. 2005; 25 (5): 473 77

[9] Johnson DD, Pretorius DH, Budorick NE, et al. Fetal lip and primary palate: three-dimensional versus two-dimensional US. Radiology 2000; 217: 236-9.

[10] Timor-Tritsch IE and Platt LD. Three-dimensional ultrasound experience in obstetrics. Curr Opin Obstet Gynecol. 2002; 14: 569-75.

[11] Scharf A, Ghazwiny MF, Steinborn A, Baier P and Sohn C. Evaluation of two dimensional versus three-dimensional ultrasound in obstetric diagnostics a prospective study. Fetal Diagn Ther. 2001; 16: 333-41.

[12] EL-Mowafi DM. Is three-dimensional ultrasound adding new for detection of congenital anomalies, Geneva Foundation for Medical Education and Research. Published March 24, 2016.

[13] Dyson RL, Pretorius DH, Budorick NE, et al. Threedimensional ultrasound in the evaluation of fetal anomalies. Ultrasound Obstet Gynecol. 2000; 16: 321-8.

[14] To WW. Prenatal diagnosis and assessment of facial clefts: where are we now? Hong Kong Med J 2012; 18: 146-52.

[15] Chan LW, Ting YH, Lao TT, et al. The use of threedimensional ultrasound does not improve training in fetal biometric measurements. J Maternal Fetal Neonatal Med. 2011; 24: 1173-5.

[16] Lam YYK and TO WWK. Evaluation of the accuracy of prenatal ultrasound assessment of facial clefts. Hong Kong J Gynaecol Obstet Midwifery 2015; 15 (1): 46-52.

[17] Kim MS. Fetal central nervous system. In: Hata T, ed. Current Topics on 3D/4D Fetal Ultrasound. Dubai, UAE. Bentham Science Publishers; 2012.

[18] Benacerraf BR. Tomography sonography of the fetus: Is it accurate to be a frontline screen for fetal malformations. J Ultrasound Med 2006; 25: 687-689.

[19] Lee YM and Simpson LL. Major fetal structural malformations: The role of new imaging modalities. Am J Med Genet Part C Semin Med Genet. 2007; 145 (C): 33-44. 